\title{
AOGS
}

Acta Obstetricia et Gymecologrica

Scandinavica

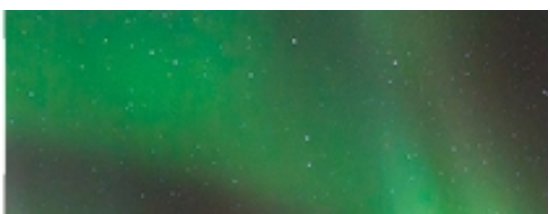

\section{The risk of complications in second pregnancy by maternal \\ BMI: The role of first-pregnancy complications, pregestational diabetes and chronic hypertension}

\begin{tabular}{|r|l|}
\hline Journal: & Acta Obstetricia et Gynecologica Scandinavica \\
\hline Manuscript ID & AOGS-19-0870.R3 \\
\hline Wiley - Manuscript type: & Original Research Article \\
\hline Author: & 11 -Sep-2020 \\
\hline & $\begin{array}{l}\text { Somplete List of Authors } \\
\text { of Obstetrics and Gynaecology, } \\
\text { Koivusalo, Saila; Helsingin ja Uudenmaan sairaanhoitopiiri } \\
\text { Gissler, Mika; THL, Information Services; Karolinska Institute, } \\
\text { Department of Neurobiology, Care Sciences and Society } \\
\text { Metsälä, Johanna; THL, Public Health Solutions }\end{array}$ \\
\hline Keywords: & $\begin{array}{l}\text { Obesity, Gestational diabetes mellitus, Hypertension in Pregnancy, } \\
\text { Preeclampsia }\end{array}$ \\
\hline
\end{tabular}

\section{SCHOLARONE Manuscripts}




\title{
The risk of complications in second pregnancy by maternal BMI: The role of first-pregnancy complications, pregestational diabetes and chronic hypertension
}

\author{
Heidi Sormunen-Harju ${ }^{1}$, Saila Koivusalo ${ }^{1}$, Mika Gissler ${ }^{2}$, Johanna Metsälä ${ }^{3}$ \\ ${ }^{1}$ Department of Obstetrics and Gynecology, University of Helsinki and Helsinki University \\ Hospital, Helsinki, Finland \\ ${ }^{2}$ Information Services Department, THL Finnish Institute for Health and Welfare, Helsinki, Finland \\ and Department of Neurobiology, Care Sciences and Society, Karolinska Institute, Stockholm, \\ Sweden \\ ${ }^{3}$ Department of Public Health Solutions, THL Finnish Institute for Health and Welfare, Helsinki, \\ Finland
}

\author{
Correspondence \\ Heidi Sormunen-Harju \\ Biomedicum 2C, PO Box 705, FI-00029 HUS, Helsinki, Finland \\ E-mail: heidi.sormunen-harju@hus.fi
}

\section{Conflicts of interest}

None 


\begin{abstract}
Introduction: Maternal obesity is associated with an increased risk of several pregnancy complications. In the second pregnancy, both previous pregnancy and other medical history provide additional information about individual morbidity risk. In this study, we assess the risk of pregnancy complications in the second pregnancy by maternal body mass index (BMI) and evaluate how first -pregnancy complications and preexisting conditions modify these associations.
\end{abstract}

Material and methods: We have used nationwide data on all women ( $\mathrm{n}=48$ 963) experiencing their first and second pregnancy between 2006 and 2013 in Finland. The associations between the full scale of maternal BMI and pregnancy complications (gestational diabetes, gestational hypertension and preeclampsia) were analyzed using logistic regression and restricted cubic spline regression models and interactions between BMI and first-pregnancy complications, pregestational diabetes or chronic hypertension were tested.

Results: The risk of pregnancy complications increased with adiposity. Unadjusted probability of second-pregnancy gestational diabetes with BMI of $25 \mathrm{~kg} / \mathrm{m} 2$ was $56 \%$ and $8.4 \%$ among women with and without first-pregnancy gestational diabetes, respectively. The corresponding figures with BMI of $30 \mathrm{~kg} / \mathrm{m} 2$ were $64 \%$ and $17 \%$. Adjusted OR (95\% CI) for second-pregnancy gestational diabetes with BMI of $25 \mathrm{~kg} / \mathrm{m} 2$ was 45 (34-59) and 3.3 (2.6-4.0) among women with and without first-pregnancy gestational diabetes, respectively, when compared to women with BMI of $20 \mathrm{~kg} / \mathrm{m} 2$ and no first-pregnancy gestational diabetes. Adjusted OR (95\% CI) for second-pregnancy gestational hypertension among women with BMI of $25 \mathrm{~kg} / \mathrm{m} 2$ was 42 (26-66) and 2.3 (1.4-3.8) among women with and without first-pregnancy hypertensive disorder, respectively, when compared to women with BMI of $20 \mathrm{~kg} / \mathrm{m} 2$ and no first-pregnancy hypertensive disorder. The risk of preeclampsia increased with adiposity independent of first-pregnancy complications.

Pregestational diabetes or chronic hypertension did not modify the association between adiposity and any of the second-pregnancy complications.

Conclusions: As maternal BMI increases, the risk of complications increases in the second pregnancy. The risk of gestational diabetes and hypertension is, however, highest among women with complications in the first pregnancy.

\title{
KEYWORDS
}


obesity, pregnancy complications, gestational diabetes, pregnancy induced hypertension, preeclampsia

\author{
Abbreviations: \\ BMI, body mass index; \\ CI, confidence interval; \\ GDM, gestational diabetes; \\ $\mathrm{GH}$, gestational hypertension; \\ HDR, Hospital Discharge Register, \\ PE, preeclampsia, \\ ICD-10, International Classification of Diseases, Tenth Revision; \\ MBR, Medical Birth Register; \\ OR, odds ratio; \\ OGTT, oral glucose tolerance test
}

\title{
Key Message
}

The risk of second-pregnancy complications increases with higher BMI. Throughout the full range of BMI, the risk of gestational diabetes and hypertension is highest in women with complications in the first pregnancy. 


\section{INTRODUCTION}

Maternal overweight and obesity are well known risk factors for several pregnancy-related complications, including gestational diabetes (GDM) and hypertensive disorders.(1,2) The risk of pregnancy complications increases with adiposity in a non-linear way and increased risk can already be seen among women in the normal range for body mass index (BMI).(3-6) Maternal obesity and pregnancy complications have both short-term and long-term adverse effects on maternal and offspring health. $(7,8)$

In clinical practice, the risk of parous women developing pregnancy complications is evaluated based on prepregnancy BMI and medical history with information about manifestation of complications in the first pregnancy. GDM recurs in 30-84\% of women.(9) Hypertensive disorder recurrence may manifest as preeclampsia (PE) or gestational hypertension $(\mathrm{GH})$ which, according to a meta-analysis of 99415 women, affect 14\% and 9\% of the following pregnancies, respectively.(10) With pregestational diabetes or chronic hypertension the recurrence risk of PE is $15-20 \%$ and $25 \%$, respectively. $(11,12)$ However, little is known about how the combination of adiposity and previous complications affects the risk of complications in the second pregnancy.

In this study we evaluated how first-pregnancy complications, GDM, GH and PE, pregestational diabetes and chronic hypertension, modify the association between BMI and second-pregnancy complications. We assessed the shape and the magnitude of the association between full-range of maternal prepregnancy BMI and second-pregnancy complications separately by the conditions found to modify the association in a large, nationwide Finnish cohort.

\section{MATERIAL AND METHODS}

\subsection{Study population and data sources}

Information on all women regarding their first and second consecutive singleton live births in Finland in 2006-2013 was extracted from the Finnish Medical Birth Register (MBR) (n=50 219 mothers). The MBR compiles information on maternal prepregnancy weight reported by the mother and height measured by midwives, both at women's first visit to the antenatal clinic usually occurring in the $10^{\text {th }}$ gestational week (mean 9.5 gestational weeks). Women with missing information on weight or height $(n=1256,2.5 \%)$ were excluded leaving 48963 women in the study 
cohort. There were no statistically significant differences in any of the background characteristics or outcomes between the study cohort and the excluded group.

The MBR covers all deliveries in Finland and is routinely linked to the Central Population Register and Cause-of-Death Register to complete the register with missing livebirths, stillbirths and infant deaths. Information on mother's sociodemographic background, maternal health care and interventions during pregnancy and delivery are recorded to the register. Information on maternal prepregnancy and pregnancy diagnoses was extracted from the Finnish Hospital Discharge Register (HDR), which includes both inpatient and outpatient data recorded by the responsible physician as International Classification of Diseases, Tenth Revision (ICD-10) codes. HDR and MBR data were linked using the encrypted unique personal identity code available in both data sources.

\subsection{Definition of exposure and outcomes}

BMI was calculated from maternal weight and height in the second pregnancy and treated as splines and categorical variables. First, BMI was categorized according to WHO classification:(13) less than $18.5 \mathrm{~kg} / \mathrm{m}^{2}$ (underweight); $18.5-24.9 \mathrm{~kg} / \mathrm{m}^{2}$ (normal weight); 25-29.9 kg/m² (pre-obesity); 30$34.9 \mathrm{~kg} / \mathrm{m}^{2}$ (obesity class I); $35-39.9 \mathrm{~kg} / \mathrm{m}^{2}$ (obesity class II); and 40 or more $\mathrm{kg} / \mathrm{m}^{2}$ (obesity class III). Second, we created a composite variable, which brought together information on BMI and first pregnancy complication (GDM, GH or PE, one composite variable for each complication). BMI was categorized into 25 categories $\left(<17 \mathrm{~kg} / \mathrm{m}^{2}\right.$ or less, $17-39 \mathrm{~kg} / \mathrm{m}^{2}$ each BMI point as a single category and $\geq 40 \mathrm{~kg} / \mathrm{m}^{2}$ ), and in each of these BMI category women were further categorized based on whether they had a complication in the first pregnancy or not.

Information on maternal adverse pregnancy outcomes and prepregnancy conditions was extracted from the MBR and the HDR. The following codes were collected: GDM (ICD-10 code O24.4); preexisting (chronic) hypertension with PE (O11); mild to moderate PE (O14.0 or O14.9); severe $\mathrm{PE}$ (O14.1); GH without significant proteinuria (O13 or O16); type 1 diabetes (E10); type 2 diabetes (E11); preexisting (pregestational) type 1 and type 2 diabetes in pregnancy (O24.0 or O24.1); hypertensive diseases (I10-15); and preexisting (chronic) hypertension complicating pregnancy $(\mathrm{O} 10)$. Information on pathologic result in glucose tolerance test was extracted as checkbox variables from the MBR. Both ICD-10 code and the check-box variable were used to define GDM. 
Since 2008 the diagnosis of GDM has been made with uniform criteria in Finland.(14) The diagnosis is based on a 2-hour 75-g oral glucose tolerance test (OGTT) with at least one abnormal plasma glucose value determined as $\geq 5.3 \mathrm{mmol} / \mathrm{l}$ (fasting), $\geq 10.0$ (1h) and $8.6 \mathrm{mmol} / \mathrm{l}(2 \mathrm{~h}$ ) and screening is performed risk-based. OGTT is recommended to be offered to all pregnant women, except those who are at low risk. Low risk parous women are defined as age $<40, \mathrm{BMI}<25 \mathrm{~kg} / \mathrm{m}^{2}$, no previous GDM or a macrosomic newborn. OGTT is performed at 24-28 weeks of gestation, but the high-risk cases (BMI $\geq 35$, GDM in prior pregnancy, glucosuria, family history of diabetes, corticosteroid therapy or polycystic ovary syndrome) were tested also at 12-16 weeks. These criteria have been applied in most parts of Finland already before 2008, but in some areas the cutoff value of $\geq 5.1 \mathrm{mmol} / 1$ for fasting glucose was used before this.

According to the guidelines generally accepted in the Finnish medical care, the following diagnostic criteria for hypertensive disorders in pregnancy apply: GH is defined by a systolic blood pressure $\geq 140 \mathrm{mmHg}$ or a diastolic blood pressure $\geq 90 \mathrm{mmHg}$ after 20 weeks of gestation in previously normotensive women. PE is defined as hypertension with concurrent new onset proteinuria ( $\geq 0.3 \mathrm{~g} / 24$ hours) or in the absence of proteinuria, new onset of thrombocytopenia, renal insufficiency, impaired liver function, pulmonary edema or cerebral or visual symptoms.(15)

\subsection{Statistical analyses}

The associations between maternal background factors, pregnancy outcomes and maternal prepregnancy BMI in WHO categories were assessed using chi-square test (categorical factors) and analysis of variance (continuous factors). The associations between BMI and GDM, GH and PE were analyzed using logistic regression.

To examine whether associations between BMI in WHO categories and the outcomes were modified by GDM, GH or PE in the first pregnancy or pregestational diabetes or chronic hypertension we included an interaction term in the models and a likelihood ratio test was used to compare the models with and without interaction term. If suggestive evidence on interaction was observed $(P$ for interaction $<.1$ ), we performed separate analyses. Only those results where the interaction was considered relevant based on separate analyses or statistically highly significant $(P$ for interaction $<.001$ ) are reported separately. In other case, the factor was returned into the pool of potential confounding factors (see below). 
Both unadjusted and adjusted models were used. Maternal age, smoking during pregnancy and socioeconomic status were considered as potential confounding factors, and first-pregnancy complications and pregestational diabetes and chronic hypertension were considered as both potential confounding factors and effect modifiers. Factors were chosen to the final adjusted models based on interaction analyses, previous knowledge, and the observed associations between confounding factors and both BMI and the outcomes in the present data.

Analyses for GDM were performed separately by first-pregnancy GDM, and the final adjusted model included maternal age, smoking, first-pregnancy GH and PE and chronic hypertension. Analyses for GH were performed separately by first-pregnancy GH or PE, and the final adjusted model included maternal age, smoking, first-pregnancy GDM and pregestational diabetes. No separate analyses for PE were performed, and the final adjusted model included maternal age, smoking, first-pregnancy GDM, GH and PE, pregestational diabetes and chronic hypertension. Women with pregestational diabetes or chronic hypertension were excluded from analysis on GDM and $\mathrm{GH}$, respectively.

We examined the shape of the association between BMI and the outcomes by fitting restricted cubic spline regression models. Based on these models, we calculated and plotted predicted probabilities and $95 \%$ confidence intervals (CI) for each outcome. To further quantify and visualize the results of the spline and the interaction analyses, we used the composite BMI-first pregnancy complication -variables in the analysis. Based on visual inspection of spline regression plots, BMI $20 \mathrm{~kg} / \mathrm{m}^{2}$ and no first pregnancy complication was set as a reference category for these variables. Results from the spline regression analyses [odds ratios (OR) with 95\% CI] are presented as the main results. Analyses were performed using STATA, version 12, software (StataCorp LP, College Station, Texas).

\subsection{Ethical approval}

This study was approved by the National Data Protection Authority and the THL Finnish Institute for Health and Welfare, which is the keeper of the MBR and the HDR 25 February 2016 (THL/265/5.05.00/2016). 


\section{RESULTS}

Demographic and clinical characteristics by BMI are outlined in Table 1. In the study population of 48963 women, 62\% were normal weight (BMI 18.5-24.9 kg/m²), 26\% overweight (BMI 25-29.9 $\mathrm{kg} / \mathrm{m}^{2}$ and $12 \%$ obese (BMI $\geq 30 \mathrm{~kg} / \mathrm{m}^{2}$ ). The mean BMI in the beginning of the second pregnancy was $24 \mathrm{~kg} / \mathrm{m}^{2}$ and ranged from 13 to $65 \mathrm{~kg} / \mathrm{m}^{2}$. The total incidences of GDM, GH and PE in the second pregnancy were 13\%, 2.6\% and 1.4\% respectively. Incidence of GDM increased by BMI class. Although the incidences of GH and PE were lower in the second than in the first pregnancy, the incidences increased by BMI class.

GDM recurred in $60 \%$, GH in $19 \%$ and PE in $17 \%$ of all pregnancies. Among women with chronic hypertension, the incidence of second-pregnancy GDM was $36 \%$ and the incidence of secondpregnancy PE was $13 \%$. Of the women with pregestational diabetes, $6.0 \%$ developed secondpregnancy GH and 5.8\% second-pregnancy PE.

The unadjusted probability of second-pregnancy GDM increased nonlinearly with BMI (Figure 1A). The association was modified by the first-pregnancy GDM $(P$ for interaction $<.001)$ and is presented separately for women with and without first-pregnancy GDM. First-pregnancy GH, PE or chronic hypertension did not modify the association between BMI and GDM ( $P$ for interaction $.806, .695$ and .190, respectively). Among women with first-pregnancy GDM, within the BMI range from $15 \mathrm{~kg} / \mathrm{m}^{2}$ to $50 \mathrm{~kg} / \mathrm{m}^{2}$, the probability of second-pregnancy GDM increased from $31 \%$ to $88 \%$, while in women without first-pregnancy GDM, the probability in the same BMI range increased from $1.3 \%$ to $37 \%$. With the shift of BMI from 25 to $30 \mathrm{~kg} / \mathrm{m}^{2}$, unadjusted probability for second-pregnancy GDM increased from $56 \%$ to $64 \%$ (1.1-fold) and from $8.4 \%$ to $17 \%$ (2-fold) among women with and without first-pregnancy GDM, respectively. Among women without firstpregnancy GDM, the adjusted OR for second-pregnancy GDM started to increase from BMI 23 $\mathrm{kg} / \mathrm{m}^{2}$ (Figure 2A). Adjusted OR (95\% CI) for second-pregnancy GDM was 45 (34-59) with BMI of $25 \mathrm{~kg} / \mathrm{m}^{2}$ and first-pregnancy GDM and 3.3 (2.6-4.0) with the same BMI and no first-pregnancy GDM. With BMI of $30 \mathrm{~kg} / \mathrm{m}^{2}$, the ORs were 55 (41-75) and 7.2 (5.6-9.1) among women with and without first-pregnancy GDM, respectively.

The unadjusted probability of second-pregnancy GH increased with BMI (Figure 1B). The association was modified by first-pregnancy GH and PE ( $P$ for interaction $<.001$ for both) and for further analysis we combined these groups as first-pregnancy hypertensive disorders. The 
Neither pregestational nor gestational diabetes modified the association between BMI and PE ( $P$ for interaction .457 and .550 , respectively). Chronic hypertension and first-pregnancy GH or PE modified the association significantly or suggestively ( $P$ for interaction .047 and .083 ). Separate analyses showed no relevance (data not shown). The unadjusted probability of second-pregnancy PE increased with adiposity from $0.9 \%$ to $7.5 \%$ within BMI range of 15 to $50 \mathrm{~kg} / \mathrm{m}^{2}$ (Figure $1 \mathrm{C}$ ). Adjusted OR (95\% CI) for second-pregnancy PE was 1.4 (0.9-2.1) among women with BMI of 25 $\mathrm{kg} / \mathrm{m}^{2}$ and $1.9(1.2-3.1)$ with BMI of $30 \mathrm{~kg} / \mathrm{m}^{2}$ (Figure $2 \mathrm{C}$ ).

\section{DISCUSSION}

To our knowledge, this is the first study to evaluate how first-pregnancy complications, pregestational diabetes and chronic hypertension modify the association between maternal prepregnancy BMI and second-pregnancy complications. We showed that although the probability of GDM and GH in the second pregnancy is greater in women with the complication in the first pregnancy, increasing adiposity is a risk factor for GDM and GH among all women. Probability of PE is low in second pregnancy, but obesity still increases the odds for this complication in the second pregnancy. Pregestational diabetes or chronic hypertension did not modify the association between BMI and second-pregnancy complications.

In our study, the OR for GDM in second pregnancy among women without prior GDM started to increase within normal range of BMI. This was also seen in our earlier study of primiparous women.(3) The results are in concordance with a recent meta-analysis of 962966 women,(16) in which dose-response relationship existed and higher maternal pre-pregnancy BMI was associated with greater risk of GDM across its full range. Previous studies have not, however, analyzed the 
association separately in the first and second pregnancy. Although concomitant risk factors, obesity and prior GDM, multiply the odds for second-pregnancy GDM, the shift from normal to overweight increases the odds for second-pregnancy GDM, even among women without GDM in firstpregnancy. However, some of the differences in the associations of adiposity and second-pregnancy GDM between the two groups, women with and without prior GDM, may be due to health care policies recommending to refer especially overweight and women with prior GDM for OGTT. This may affect our results by detecting the condition more often in obese women or in women with prior GDM, and underestimating the risk of GDM in lean women or those without prior GDM.

The etiology of hypertension and diabetes overlap and, in addition to obesity, common pathways are thought to be inflammation, oxidative stress and insulin resistance.(17) Chronic hypertension has been shown to increase the incidence of GDM,(18) but the association between BMI and GDM was not modified by prior GH, PE or chronic hypertension in our study.

The unadjusted probability of GH was low in women without first-pregnancy hypertensive disorder, but the OR for second-pregnancy GH increased with BMI in all women. This observation is in line with findings from a recent meta-analysis of 265270 women. (19) In our study the odds for second-pregnancy GH at any given BMI was higher among women with than those without firstpregnancy GH or PE .

Incidence of PE is low in parous women and a rate of $1.7 \%$ was demonstrated in a Swedish cohort.(20) Our study is in concordance with this observation. Although the number of women with PE in our study was low, increasing adiposity was associated with higher OR for PE. No significant nor relevant modification in the association between BMI and PE was seen for gestational or pregestational diabetes, or first-pregnancy or chronic hypertensive disorders. Studies with a larger number of women with PE are needed to confirm or refute these findings. In addition, PE is more than one disease (21) but we were unable to make a distinction between early and late onset PE. One more factor that we were unable to account for in this study, was the use of aspirin for the prevention of PE among women with a history of hypertensive disorders.

One of the strengths of our study is that it presents a large nationwide population-based cohort. We have complemented the information obtained from the MBR with data from the HDR. The coverage and quality of Finnish registers is high.(22) The positive predictive value of complications of pregnancy and childbirth in the HDR has been found to be $94 \%,(23)$ and the proportion of 
missing data in the registers is low. Maternity and child welfare clinics are free of charge in Finland resulting in attendance by the entire pregnant population.(24) Nonetheless, prepregnancy BMI was self-reported which may lead to some underestimation. However, a large systematic review showed that misclassification was moderate and did not bias associations between prepregnancy BMI and pregnancy outcomes.(25) Another limitation of the study is, that despite the large number of women, the number of patients with pregestational diabetes or chronic hypertension was small and some interactions may have been undetected.

Maternal prepregnancy overweight and obesity increase the risk of pregnancy complications. Our study presents new information about how the associations between BMI and complications in second pregnancy are modified by prior conditions. Susceptibility to a pregnancy complication like GDM, GH or PE, whether caused by genetic predisposition or life style factors, emerges in the firstpregnancy and provides a strong signal for the increased risk of a woman to develop pregnancy complications in the second pregnancy. However, increased adiposity is harmful for all women, even those with no prior complications. Modest changes in prepregnancy BMI may substantially increase the risk of pregnancy complications and more attention needs to be paid to weight gain even before reaching obesity. All women, even when there have been no complications in the first pregnancy, should be advised on the impact of overweight and obesity on future pregnancies and offered lifestyle counseling aimed at attaining healthy prepregnancy weight. National policy solutions are also needed to tackle the crisis of the continuously increasing epidemic of obesity.

\section{CONCLUSION}

The risk of second-pregnancy complications increases with BMI, even if the first pregnancy has been uncomplicated. This finding warrants attention from the healthcare personnel counselling and treating pregnant women. Across the full range of BMI, the risk of GDM and GH is, however, highest in women with complications in the first pregnancy.

\section{REFERENCES}

(1) Chu SY, Callaghan WM, Kim SY, et al. Maternal obesity and risk of gestational diabetes mellitus. Diabetes Care. 2007;30:2070-2076.

(2) Antza C, Cifkova R, Kotsis V. Hypertensive complications of pregnancy: A clinical overview. Metabolism. 2018;86:102-111. 
(3) Metsala J, Stach-Lempinen B, Gissler M, Eriksson JG, Koivusalo S. Risk of Pregnancy Complications in Relation to Maternal Prepregnancy Body Mass Index: Population-Based Study from Finland 2006-10. Paediatr Perinat Epidemiol. 2016;30:28-37.

(4) Bodnar LM, Catov JM, Klebanoff MA, Ness RB, Roberts JM. Prepregnancy body mass index and the occurrence of severe hypertensive disorders of pregnancy. Epidemiology. 2007;18:234-239.

(5) Mutsaerts MA, Groen H, Buiter-Van der Meer A, et al. Effects of paternal and maternal lifestyle factors on pregnancy complications and perinatal outcome. A population-based birth-cohort study: the GECKO Drenthe cohort. Hum Reprod. 2014;29:824-834.

(6) Schummers L, Hutcheon JA, Bodnar LM, Lieberman E, Himes KP. Risk of adverse pregnancy outcomes by prepregnancy body mass index: a population-based study to inform prepregnancy weight loss counseling. Obstet Gynecol. 2015;125:133-143.

(7) Godfrey KM, Reynolds RM, Prescott SL, et al. Influence of maternal obesity on the long-term health of offspring. Lancet Diabetes Endocrinol. 2017;5:53-64.

(8) Marchi J, Berg M, Dencker A, Olander EK, Begley C. Risks associated with obesity in pregnancy, for the mother and baby: a systematic review of reviews. Obes Rev. 2015;16:621-638.

(9) Kim C, Berger DK, Chamany S. Recurrence of gestational diabetes mellitus: a systematic review. Diabetes Care. 2007;30:1314-1319.

(10) van Oostwaard MF, Langenveld J, Schuit E, et al. Recurrence of hypertensive disorders of pregnancy: an individual patient data metaanalysis. Am J Obstet Gynecol. 2015;212:624.e1-17.

(11) Bramham K, Parnell B, Nelson-Piercy C, Seed PT, Poston L, Chappell LC. Chronic hypertension and pregnancy outcomes: systematic review and meta-analysis. BMJ. 2014;348:g2301.

(12) Weissgerber TL, Mudd LM. Preeclampsia and diabetes. Curr Diab Rep. 2015;15:9.

(13) Obesity: preventing and managing the global epidemic. Report of a WHO Consultation (WHO Technical Report Series 894). WHO 2000.

(14) Kaaja R, Kivelä R, Kukkonen-Harjula K, et al. Raskausdiabetes : Käypä hoito -suositus. [Gestational diabetes: current care guidelines] (in Finnish) Duodecim. 2008;124:1556-69.

(15) American College of Obstetricians and Gynecologists, Task Force on Hypertension in Pregnancy. Hypertension in pregnancy. Report of the American College of Obstetricians and Gynecologists' Task Force on Hypertension in Pregnancy. Obstet Gynecol. 2013;122:1122-1131.

(16) Najafi F, Hasani J, Izadi N, et al. The effect of prepregnancy body mass index on the risk of gestational diabetes mellitus: A systematic review and dose-response meta-analysis. Obes Rev. 2019;20:472-486.

(17) Cheung BM, Li C. Diabetes and hypertension: is there a common metabolic pathway? Curr Atheroscler Rep. 2012;14:160-166. 
(18) Leon MG, Moussa HN, Longo M, et al. Rate of Gestational Diabetes Mellitus and Pregnancy Outcomes in Patients with Chronic Hypertension. Am J Perinatol. 2016;33:745-750.

(19) Santos S, Voerman E, Amiano P, et al. Impact of maternal body mass index and gestational weight gain on pregnancy complications: an individual participant data meta-analysis of European, North American and Australian cohorts. BJOG. 2019;126:984-995.

(20) Hernandez-Diaz S, Toh S, Cnattingius S. Risk of pre-eclampsia in first and subsequent pregnancies: prospective cohort study. BMJ. 2009;338:b2255.

(21) Robillard PY, Dekker G, Scioscia M, et al. Increased BMI has a linear association with lateonset preeclampsia: A population-based study. PLoS One. 2019;14:e0223888.

(22) Gissler M HJ. Finnish health and social welfare register in epidemiological research. Norsk Epidemiologi $=$ Norwegian Journal of Epidemiology. 2004;14:113-120.

(23) Sund R. Quality of the Finnish Hospital Discharge Register: a systematic review. Scand J Public Health. 2012;40:505-515.

(24) Hartikainen AL. Äitiysneuvolakäynnit lisääntyvät jatkuvasti - olisiko aihetta toiminnan arviointiin? (Antenatal care visits are in constant increase - is there need for reconsidering?). in Finnish. Suom Lääkäril = Finnish Medical Journal. 2003;58:2437-2440.

(25) Headen I, Cohen AK, Mujahid M, Abrams B. The accuracy of self-reported pregnancy-related weight: a systematic review. Obes Rev. 2017;18:350-369. 


\section{Legends}

TABLE 1. Maternal characteristics of the cohort by prepregnancy body mass index categories in the second pregnancy

FIGURE 1. Expected unadjusted probability of (A) gestational diabetes (GDM), (B)gestational hypertension, and $(\mathrm{C})$ preeclampsia $(\mathrm{PE})$, in $2^{\text {nd }}$ pregnancy by maternal prepregnancy body mass index. Dashed lines represent 95\% confidence intervals.

FIGURE 2 . The association between maternal prepregnancy body mass index and the odds ratio for $2^{\text {nd }}$ pregnancy complication. The odds for (A) gestational diabetes (GDM) are adjusted for maternal age, smoking, chronic hypertension and $1^{\text {st }}$ pregnancy gestational hypertension and preeclampsia. The odds for (B) gestational hypertension are adjusted for maternal age, smoking, pregestational diabetes and $1^{\text {st }}$ pregnancy gestational diabetes. The odds for $(\mathrm{C})$ preeclampsia (PE) are adjusted for maternal age, smoking, pregestational diabetes and chronic hypertension, and $1^{\text {st }}$ pregnancy gestational diabetes, gestational hypertension and preeclampsia. Bars represent 95\% confidence intervals. 
TABLE 1 Maternal characteristics of the cohort by prepregnancy body mass index categories in the second pregnancy

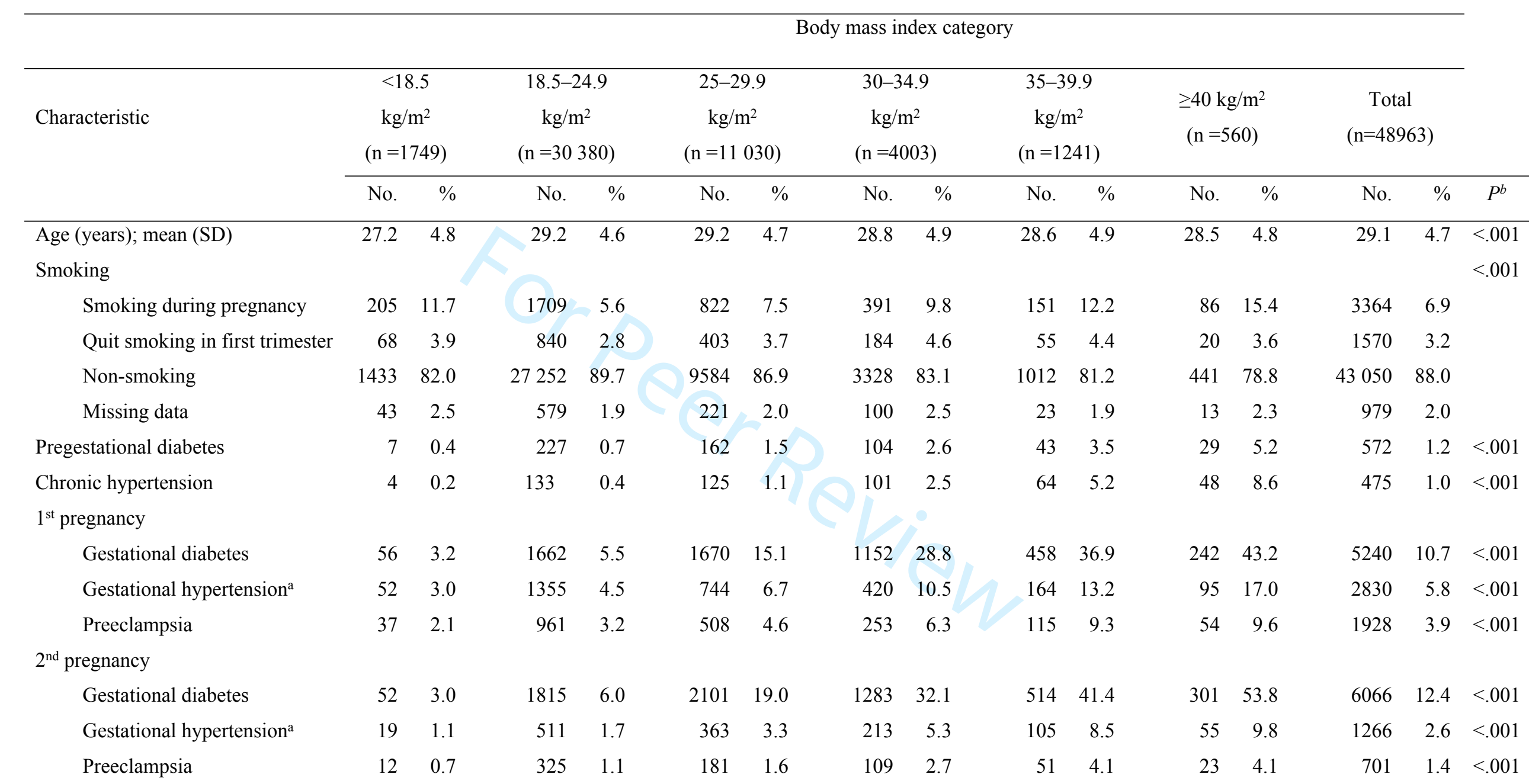

${ }^{a}$ Excluding women with further diagnosed preeclampsia

${ }^{\mathrm{b}} P$ value obtained from analysis of variance (maternal age) or chi2-test (other factors) 


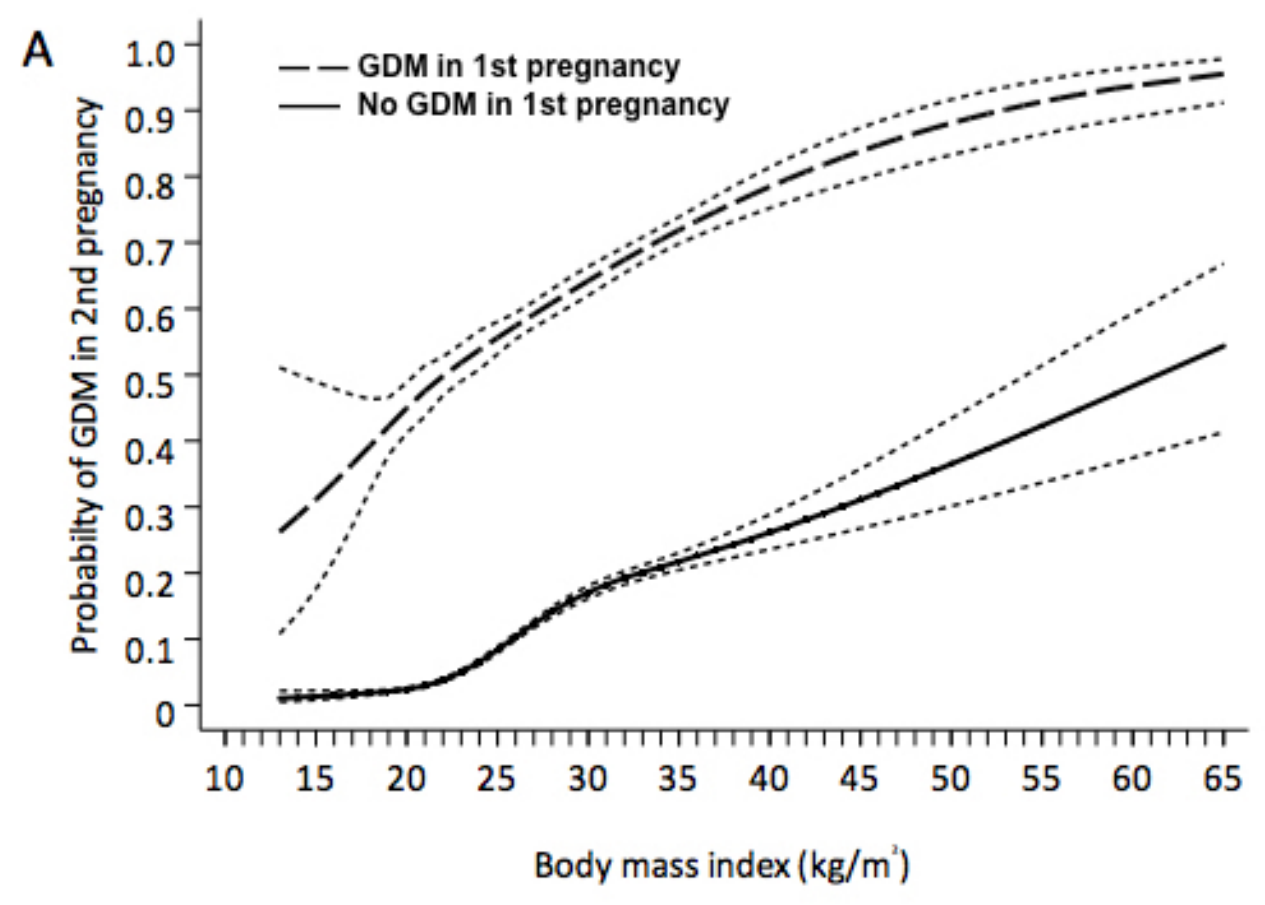

FIGURE 1 Expected unadjusted probability of gestational diabetes (A), gestational hypertension (B), and preeclampsia $(C)$ in 2nd pregnancy by maternal prepregnancy body mass index. Dashed lines represent $95 \%$ confidence intervals.

$179 \times 130 \mathrm{~mm}(72 \times 72$ DPI $)$ 


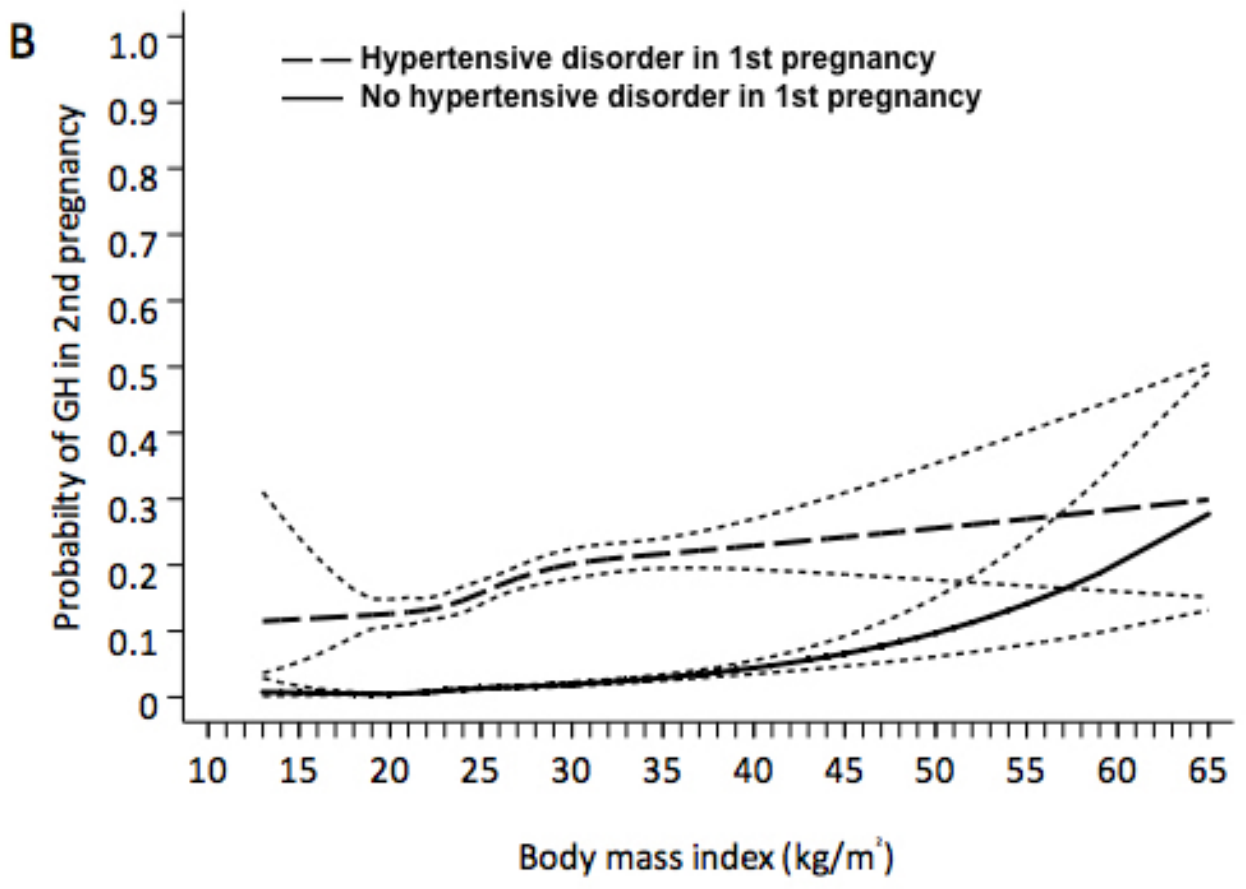

179x130mm (72 x 72 DPI) 


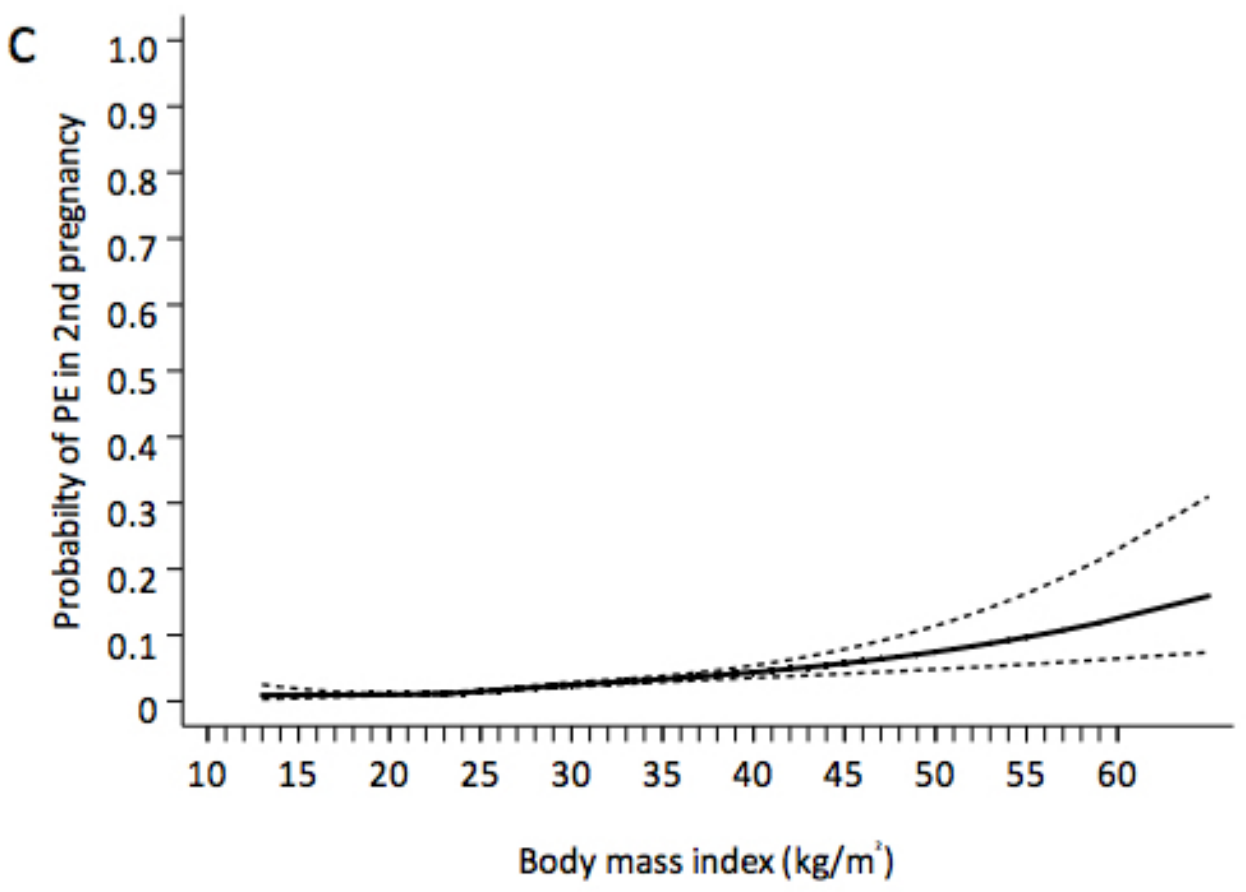

179x130mm (72 x 72 DPI) 


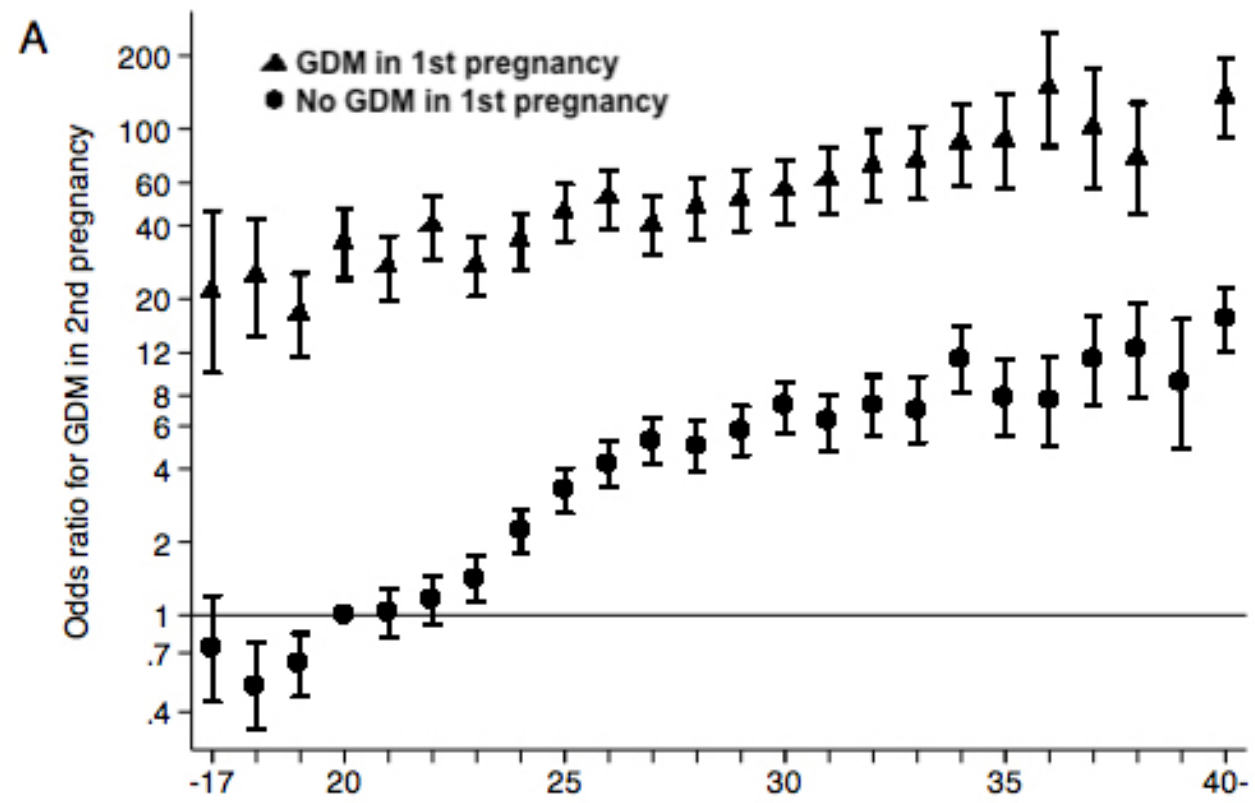

Body mass index $\left(\mathrm{kg} / \mathrm{m}^{2}\right)$

FIGURE 2 The association between maternal prepregnancy body mass index and the odds ratio for 2 nd pregnancy complication. The odds for gestational diabetes (A) are adjusted for maternal age, smoking, chronic hypertension and 1st pregnancy gestational hypertension and preeclampsia. The odds for gestational hypertension (B) are adjusted for maternal age, smoking, pregestational diabetes and 1st pregnancy gestational diabetes. The odds for preeclampsia (C) are adjusted for maternal age, smoking, chronic hypertension and pregestational diabetes, and 1st pregnancy gestational diabetes, gestational hypertension and preeclampsia. Bars represent $95 \%$ confidence intervals.

$179 \times 130 \mathrm{~mm}(72 \times 72 \mathrm{DPI})$ 
B

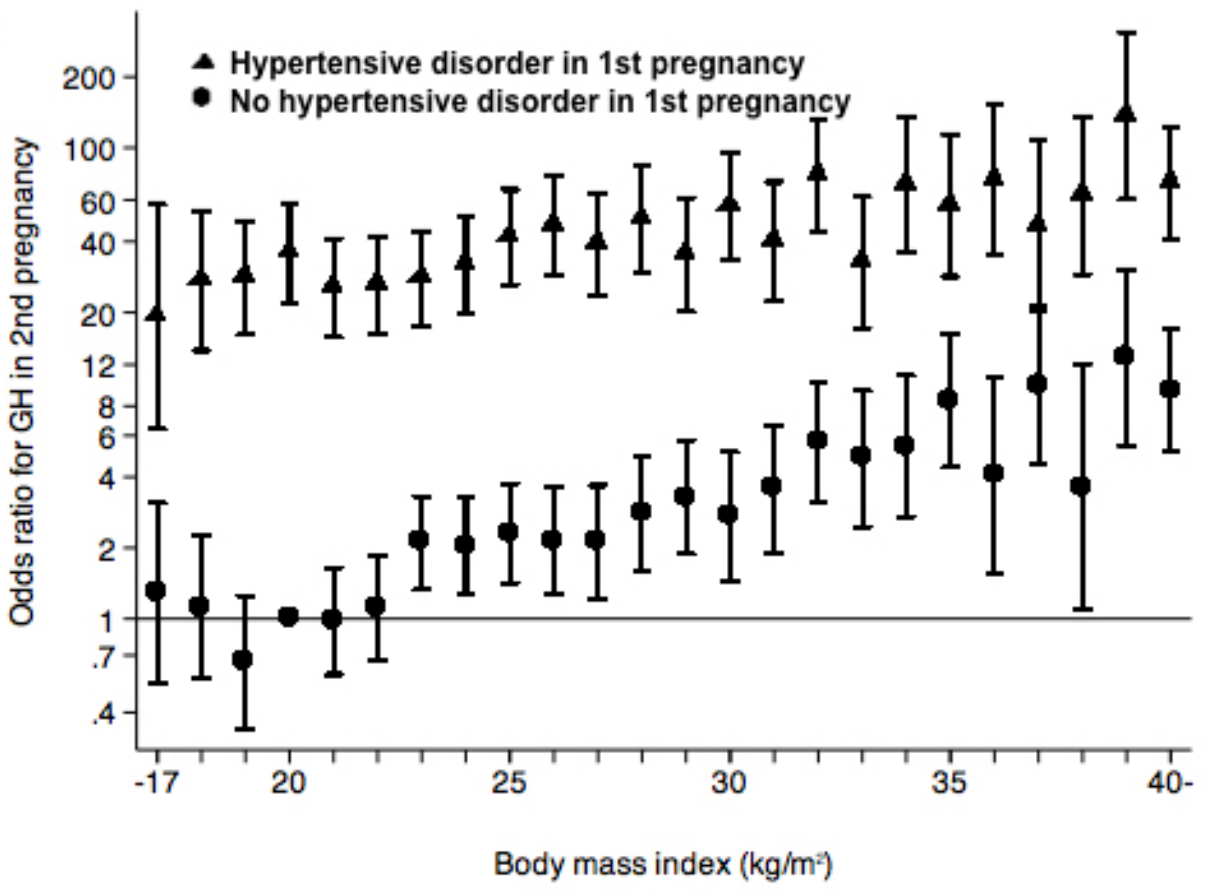

$179 \times 130 \mathrm{~mm}(72 \times 72 \mathrm{DPI})$ 


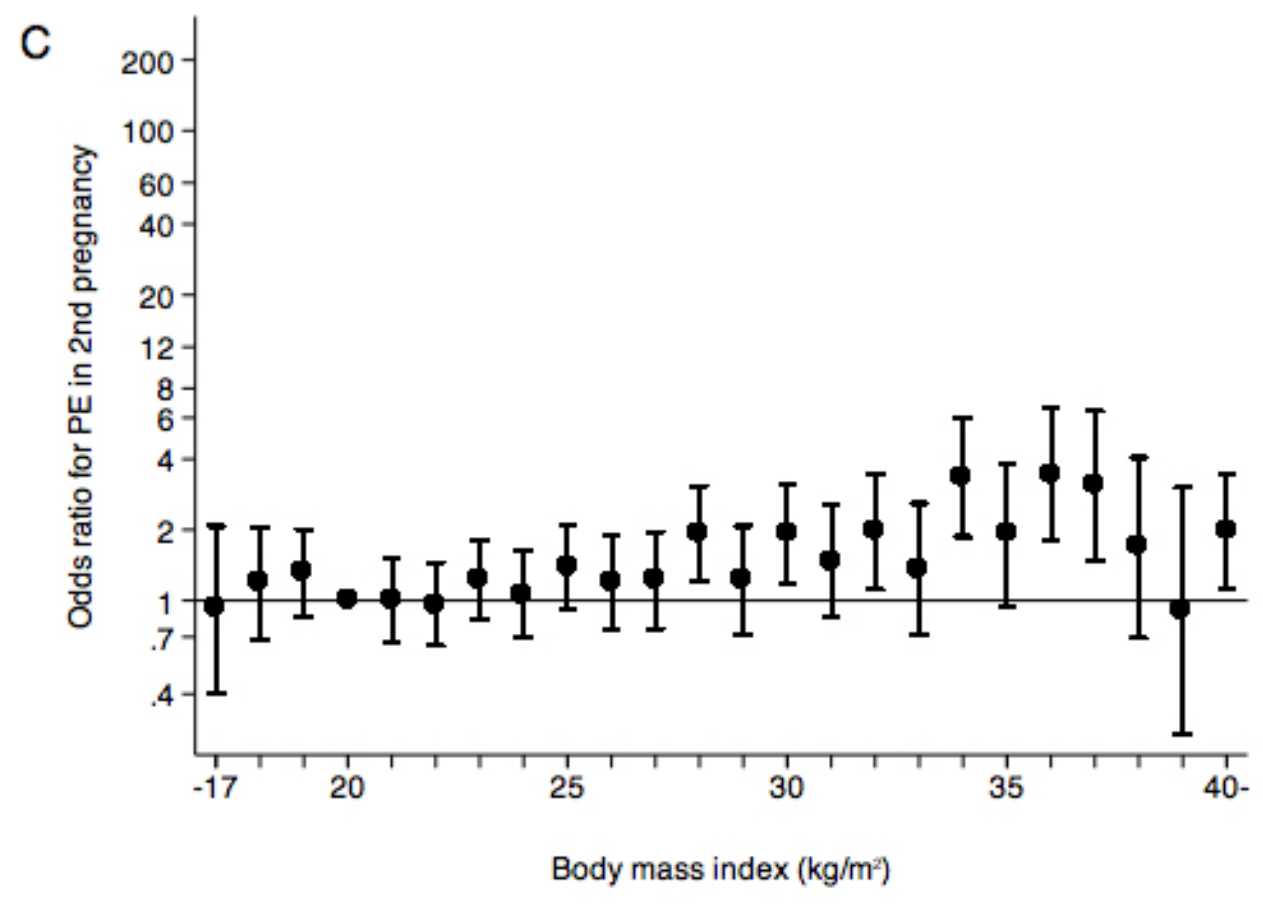

$179 \times 130 \mathrm{~mm}(72 \times 72 \mathrm{DPI})$ 